\title{
Rocket Science for Educators; K-12 Techniques for Science Technology Engineering and Mathematics
}

\author{
Todd H. Treichel ${ }^{1}$ \\ American Institute of Aeronautics and Astronautics and \\ Orbital Technologies Corporation
}

\begin{abstract}
The Wisconsin AIAA chapter has leveraged the talent of its members to provide a variety of outreach opportunities for precollege aged students. Hands-on demonstrations, visual aids, and real-life space flight examples provide a foundation for bringing pre-college aged students face-to-face with space-related science, designed hardware, technology, and potential benefits; increased interest in aerospace and space related fields that lead to study at the university level followed by career. The Rocket Science for Educators program consists of a workshop used to assist schools in implementing rocket science into respective math or science curriculums. Participating educators attend a weekend workshop and receive a set of rocket science materials that they may take back to their respective schools. This workshop is taught by aerospace professionals where they provide a unique opportunity for teachers to provide meaningful activities in their classrooms and improve student performance in the fields of science, technology, engineering, and mathematics.
\end{abstract}

\section{Nomenclature}

$\begin{array}{lll}A I A A & = & \text { American Institute for Aeronautics and } \\ C G & = & \text { Center of gravity } \\ C M & = & \text { Center of mass } \\ G & = & \text { Acceleration force due to gravity } \\ H I-R E L & = & \text { High reliability } \\ V & = & \text { Velocity } \\ R H & = & \text { Relative humidity } \\ \text { NASA } & = & \text { National Aeronautics and Space } \\ O R B I T E & = & \text { Orbital Technologies Corporation } \\ \text { STEM } & = & \text { Science Technology Engineering and } \\ W S G C & = & \text { Wisconsin Space Grant Consortium }\end{array}$

\section{Introduction}

The Wisconsin section of AIAA is based in Madison, Wisconsin and has a current membership of approximately 80 members and has recently won the 2009 Harry Staubs Pre-College Outreach Award. The award is presented annually to sections that have developed and implemented an outstanding pre-college (k-12) outreach program that provides quality educational resources for teachers in science, technology, engineering, and mathematics (STEM) subject areas. In 2010 AIAA-Wisconsin was awarded an outreach grant from the Wisconsin Space Grant Consortium (WSGC) and successfully administered a Rocket Science for Educators workshop for K-12 educators in Madison, Wisconsin.

\section{Goals and Value of Project}

A decline in both the quantity and quality of students pursuing careers in STEM is widely noted in policy reports, the press, education, and government. Fears of increasing global competition compound the perception that there has been a drop in the supply of high-quality students

\footnotetext{
1 Systems Engineer, Space Center, 1212 Fourier Drive, Madison, Wisconsin, USA, AIAA Senior Member.
} 
moving up through the STEM pipeline in the United States. A recent article published on February 12, 2010, by the Milwaukee Journal Sentinel, reveals the following (Miller, 2010):

Grade school science teachers aren't doing the best job of informing their students about careers in science and engineering, according to a new survey of students from the American Society for Quality (ASQ). The survey of more than 1,110 students, which was done in December 2009, tried to discover how well teachers translate their knowledge and passion for science to getting children excited about engineering and science careers. It found that $63 \%$ of students think their teachers are not doing a good job of talking to them about engineering careers, and $42 \%$ said their teachers aren't good at showing them how science can be used in a career.

Among the survey's findings:

- $85 \%$ of students said their teachers deserve at least a " $B$ " grade when it comes to knowledge about science topics, and 55\% gave them an "A."

- Nearly one third of students give their teachers a " $C$ " or lower for making science more exciting and fun to learn and assigning fun hands-on projects in the classroom.

- Students in grades 3-6 rate their science teachers higher for making science exciting and hands-on than students in grades 7-12 rate their science teachers.

- $72 \%$ of students in 3-12 grades think a person needs to do well in science and math to get a good paying job in the future.

- As students get older (7-12 grades) however, they are less likely to believe that science and math are necessary to getting a good paying job.

The Wisconsin AIAA chapter has leveraged the talent of its members to provide a variety of outreach opportunities for precollege aged students. Hands-on demonstrations, visual aids, and real-life space flight examples provide a foundation for bringing pre-college aged students face-to-face with space-related science, designed hardware, technology, and the potential benefits; increased interest in aerospace and space related fields that lead to study at the university level followed by career. Section officers discussed and reviewed a compilation of various outreach projects summarizing a three year period covering 2006 - 2008. A survey form was constructed in an attempt to measure effectiveness of outreach efforts.

In 2009 the Wisconsin AIAA conducted a series of workshops on Physics of Propulsion and Space Flight. To test the effectiveness of these workshops, participants were asked to participate in a pre and post workshop survey. Survey results are summarized in Figure 1 where students sampled, grades six through eight, considered math and science important but only $60 \%$ were interested in STEM subjects.

At the conclusion of the workshop series, students again were surveyed where a $35 \%$ increase in STEM interest resulted. 
Over the last century, America's economy has shifted from an agricultural and industrial focus to one that requires greater scientific and mathematical knowledge as well as technological expertise. According to the Bureau of labor Statistics, of the thirty fastest growing occupations projected for 2016, twenty-two of them are in STEM related fields. AIAA Wisconsin members and involved teachers were intrigued by these measureable results. Thus, causing

WI AIAA 2009 Outreach Survey Results

(35 Students, $6^{\text {th }}-8^{\text {th }}$ Grade)

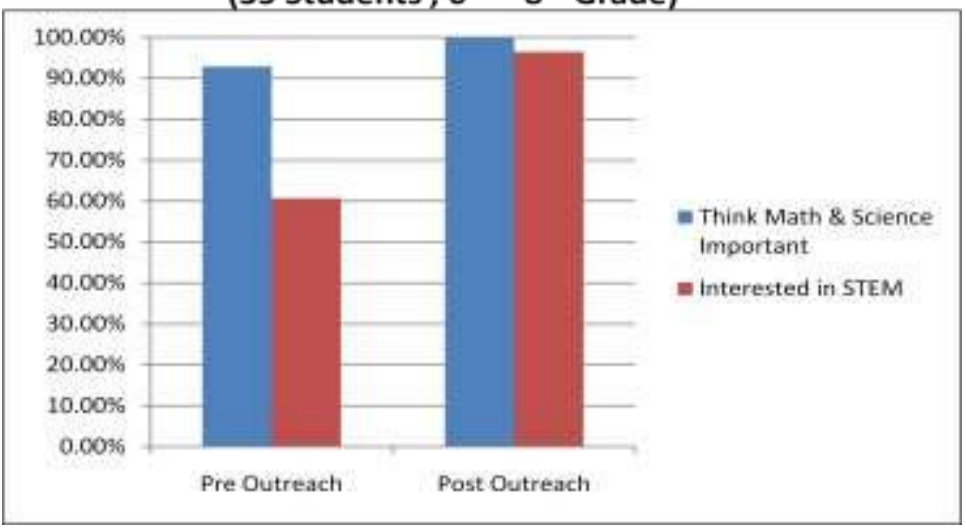

Figure 1, 2009 outreach survey summary.

the development of an educational outreach program that reaches out to K-12 teachers.

The goal of the Rocket Science for Educators workshop is to assist schools in implementing rocket science into respective math or science curriculums. A proposal was submitted to the Wisconsin Space Grant Consortium (WSGC) to assist with funding the newly designed program. The Rocket Science for Educators workshop was designed specifically for educators from public and private institutions and those educators experienced with teaching math or science subjects. Participating educators attend a weekend and receive a set of rocket science materials that they may take back to the respective schools for use and implementation. A workshop taught by aerospace professionals provides a unique opportunity for teachers to provide meaningful activities in their classrooms and improve student performance in the fields of science, technology, engineering, and mathematics.

\section{Rocket Science for Educators}

In fall of 2010, a WSGC grant funded Rocket Science for Educators workshop was conducted in Madison, Wisconsin where a total of fourteen educators were recruited to attend a rocket science workshop at no charge. Workshop attendees consisted of math, science, art, and special needs teachers from K-12 institutions, primarily from the southern part of the state (see Figure 2). The workshop was conducted at Orbital Technologies Corporation (ORBITEC), located in Madison, Wisconsin. The workshop utilized aerospace topics to provide STEM education to educators for preparing today's students for tomorrow's jobs allowing them to be competitive in an increasingly global economy.

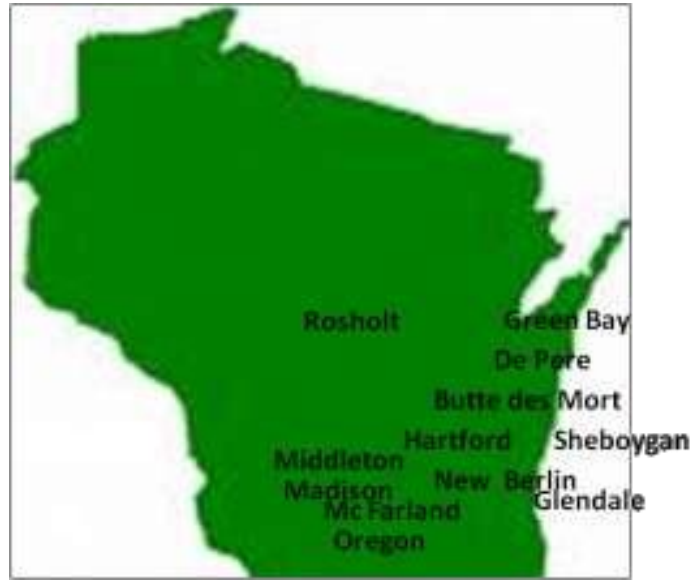

Figure 2. Geographical origins of 2010 workshop participants. 

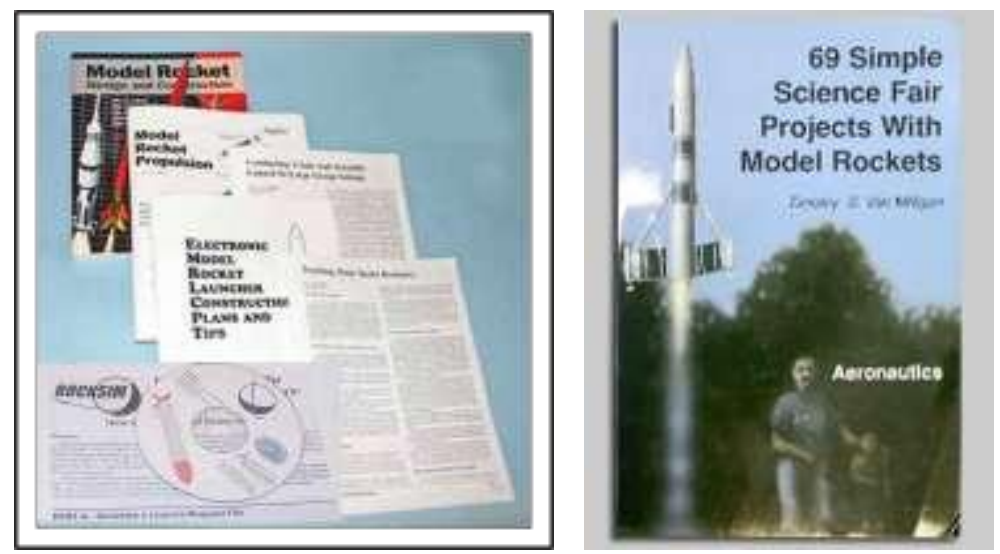

Figure 3. Rocket design simulation software and reference materials.

Table 1 illustrates workshop topics and how each topic relates to an educational discipline. Lectures and hands on activities were conducted including design, construction, planned experimentation, altitude analysis and differential pressure, static rocket engine firing, and the launching of a payload capable rocket. At the close of the workshop, instructors provided

constructive feedback accompanied by a short competency quiz to demonstrate participants' mastery of course subject matter. Educators were issued an achievement plaque and a set of materials that can be used for implementation into their respective math or science curriculums. Curriculum adaptable aerospace software license (see
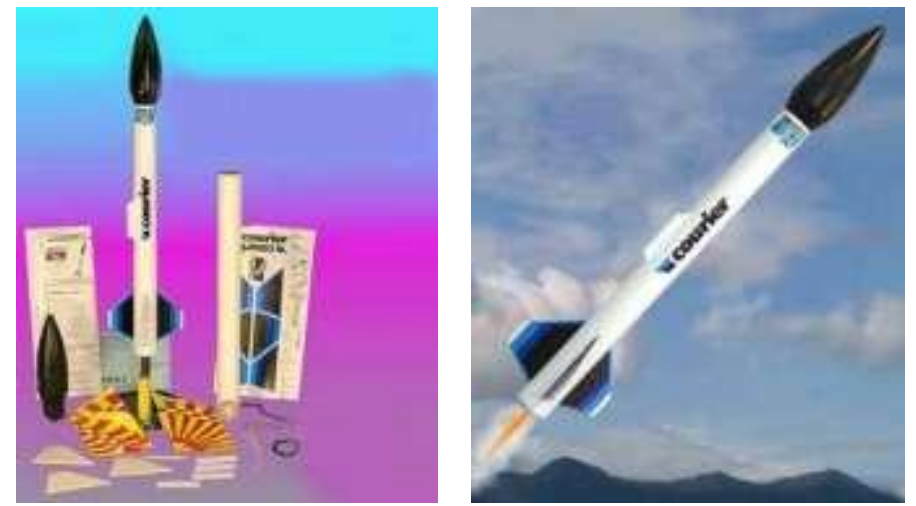

Figure 4. Payload capable model rocket.

Figure 3), and rocket construction material (see Figure 4) were provided to each participant completing the workshop. Highlights of the workshop consisted of a series of lectures which included demonstration (static) firing of potassium nitrate solid fuel, composite solid fuel, and hybrid rocket engines (see Figure 5). Safety rules for storage and handling of propellant materials was

discussed and making a science project out of home-made rocket engines was discouraged for reasons of safety. Extensive time was spent using RockSim design software to demonstrate rocket design techniques, 3D imaging, and flight simulation (see Figure 6) followed by construction and flight of a payload capable rocket. RockSim is a computer program that allows you to design any size rocket, and then simulate its flight to see how high, and how fast it will fly. Prior to teachers building their payload capable rockets, an analysis of various payload weights were conducted with different engine thrust parameters to determine if the actual flight would be stable and safe to launch. The purpose of lectures, demonstrations, and take-home materials was to provide educators with educational tools that:

1. Provide basic knowledge of aerospace engineering and rockets.

2. Provide rocket design and simulation software training and user license.

3. Ability to conduct flight experiments using an electronic altimeter.

4. Allows educator to have access to reference material for rocket propulsion.

5. Provide knowledge of how to build an electric powered launch pad.

6. Assure safety and enable educator with skills to properly conduct a rocket launch for educational groups. 
7. Build interest and excitement about STEM.

8. Provide an opportunity for hands-on experiences with STEM subjects by designing, building, launching, and recovering payload capable rocket.

9. Raise student educational aspirations, knowledge of STEM, and interest in pursuing a career in aerospace.

10. Improve teaching of STEM subjects by collaborating with teacher preparation and professional development activities.

Table 1. Rocket science for educator's workshop curriculum.

\begin{tabular}{|c|c|c|c|c|c|c|c|c|c|c|c|}
\hline $\begin{array}{l}\text { Education } \\
\text { Module }\end{array}$ & 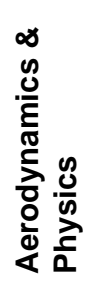 & 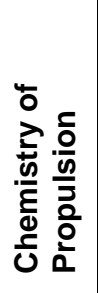 & 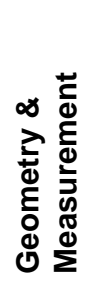 & 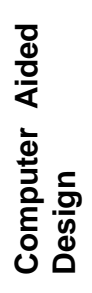 & 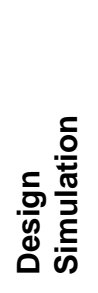 & 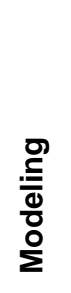 & 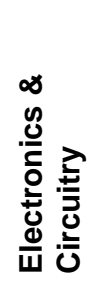 & 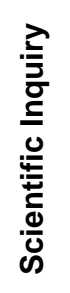 & 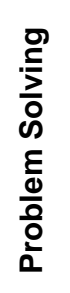 & 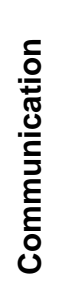 & 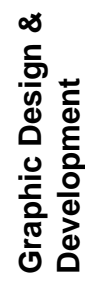 \\
\hline Newton's Laws & $\mathrm{X}$ & & $\mathrm{X}$ & & & & & & $\mathrm{x}$ & & \\
\hline $\begin{array}{l}\text { Principles of } \\
\text { Flight }\end{array}$ & $\mathrm{X}$ & & $\mathrm{X}$ & $\mathrm{X}$ & $\mathrm{X}$ & & & & & & \\
\hline Rocket Engines & $\mathrm{X}$ & $X$ & $X$ & $X$ & $X$ & $X$ & $X$ & & & & \\
\hline Rocket Stability & $\mathrm{X}$ & $\mathrm{X}$ & $x$ & $\mathrm{X}$ & $x$ & $x$ & & & & & \\
\hline $\begin{array}{l}\text { Techniques of } \\
\text { Rocket Design }\end{array}$ & $\mathrm{X}$ & $\mathrm{X}$ & $\mathrm{X}$ & $\mathrm{X}$ & $\mathrm{X}$ & $\mathrm{X}$ & & $\mathrm{x}$ & $\mathrm{X}$ & $x$ & \\
\hline Payload Science & $X$ & $X$ & $X$ & $x$ & $X$ & $\mathrm{x}$ & $x$ & $x$ & $x$ & $x$ & $\mathrm{X}$ \\
\hline Recovery & $\mathrm{X}$ & & $\mathrm{X}$ & $\mathrm{X}$ & $\mathrm{X}$ & $x$ & & $x$ & $\mathrm{X}$ & $\mathrm{X}$ & $\mathrm{X}$ \\
\hline $\begin{array}{l}\text { Planned } \\
\text { Experimentation }\end{array}$ & $\mathrm{X}$ & $\mathrm{X}$ & $\mathrm{X}$ & $\mathrm{X}$ & $\mathrm{X}$ & $\mathrm{X}$ & & $x$ & $\mathrm{X}$ & $\mathrm{x}$ & \\
\hline $\begin{array}{l}\text { Rocket } \\
\text { Construction }\end{array}$ & & & $\mathrm{X}$ & $\mathrm{X}$ & $\mathrm{X}$ & $\mathrm{x}$ & $\mathrm{x}$ & & $\mathrm{x}$ & $x$ & $\mathrm{X}$ \\
\hline $\begin{array}{l}\text { Engineering } \\
\text { Change Mgt. }\end{array}$ & & & $\mathrm{X}$ & $\mathrm{X}$ & $\mathrm{X}$ & $\mathrm{x}$ & $x$ & & $\mathrm{X}$ & $\mathrm{x}$ & $\mathrm{X}$ \\
\hline $\begin{array}{l}\text { Safety } \\
\text { Procedures }\end{array}$ & & $\mathrm{X}$ & & & & & $\mathrm{X}$ & & & $\mathrm{x}$ & \\
\hline Weather & $X$ & & & & $X$ & & & $\mathrm{X}$ & $x$ & $x$ & \\
\hline $\begin{array}{l}\text { Launch Pad \& } \\
\text { Controls }\end{array}$ & $\mathrm{X}$ & & $\mathrm{X}$ & & & & $\mathrm{X}$ & & & $x$ & \\
\hline $\begin{array}{l}\text { Analysis \& } \\
\text { Reporting }\end{array}$ & & & & & & & & $x$ & $\mathrm{x}$ & $x$ & $\mathrm{X}$ \\
\hline
\end{tabular}




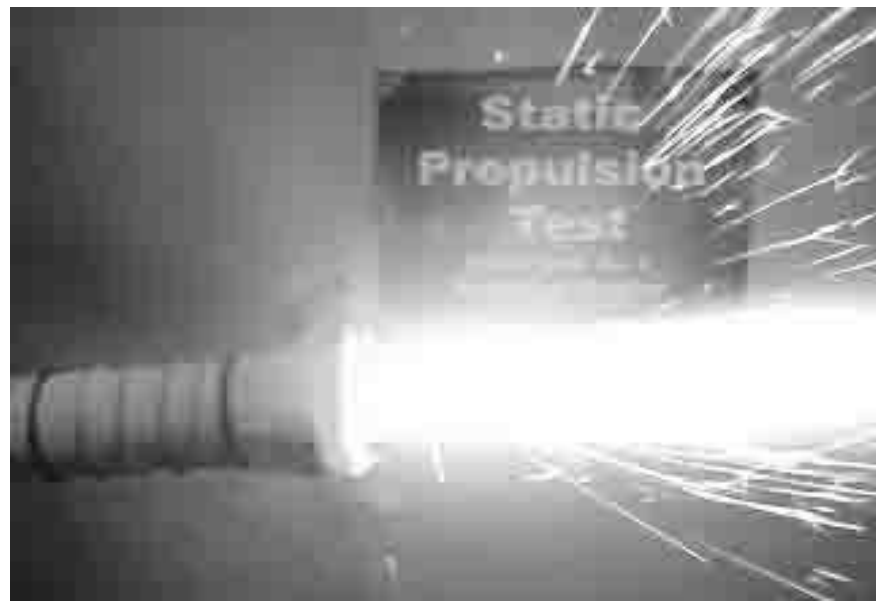

Figure 5. Static firing of rocket engines
The purpose of workshop presentations was to give teachers a strong foundation in rocketry, understand the physics and science behind rocket propulsion, and bring a motivating set of materials and subject matter back to their classrooms. A particular emphasis on rocket propulsion and rocket stability was contained in take-home binder to accompany rocket propulsion discussions, talks about the physics, how rockets produce thrust, the types of propellants

used in rockets, characteristics of high and low thrust motors, the nomenclature for rocket motors, the thrust curve, and how to select the best type of engine for a rocket and desired mission.

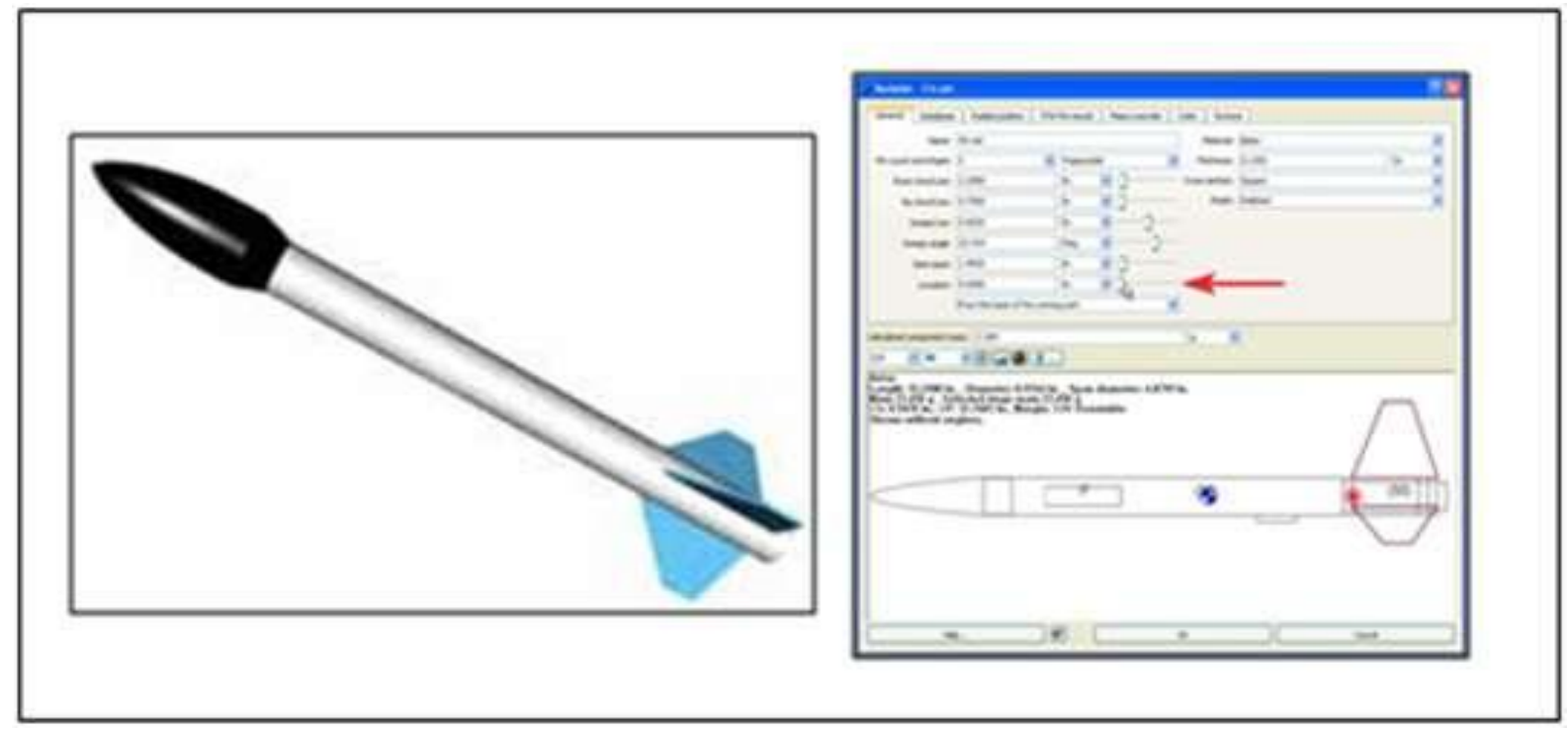

Figure 6. RockSim software design and simulation.

At the conclusion of launching the various payloads a post-launch review was conducted to discuss lessons learned and the process of corrective actions for improvement and future experimentation. Prior to adjournment, a survey was administered to test workshop effectiveness where each educator was asked to score the workshop for relevance and fit-for-use within their respective curriculums. The scoring scale was $1-10$, where 1 indicates that they should have stayed home and 10 indicating that the workshop exceeded expectations). Workshop survey results are illustrated in Figure 7. An average score of 8.9 revealed a worthwhile effort and a desire among AIAA Wisconsin section members to pursue this type of outreach effort in the future. Figure 9 illustrates participants in a group photo at the conclusion of the educator workshop. 


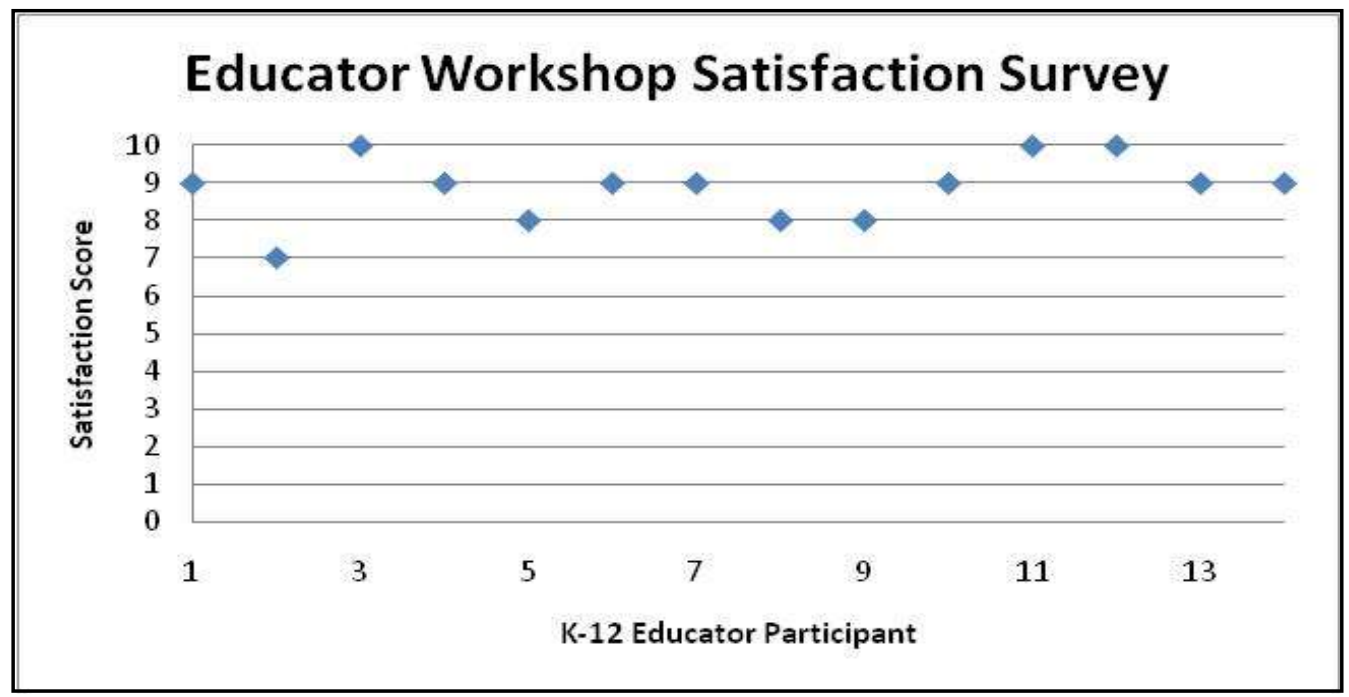

Figure 7. 2010 Rocket Science for Educators workshop survey results.

\section{Conclusion}

In June 2011 the 14 educator workshop participants were contacted and asked to respond to five questions about their use of workshop materials and most importantly if respective activities improved student interest in STEM. Out of the 14 educators 11 responded to the survey and yes answers were recorded and are illustrated in Figure 8.

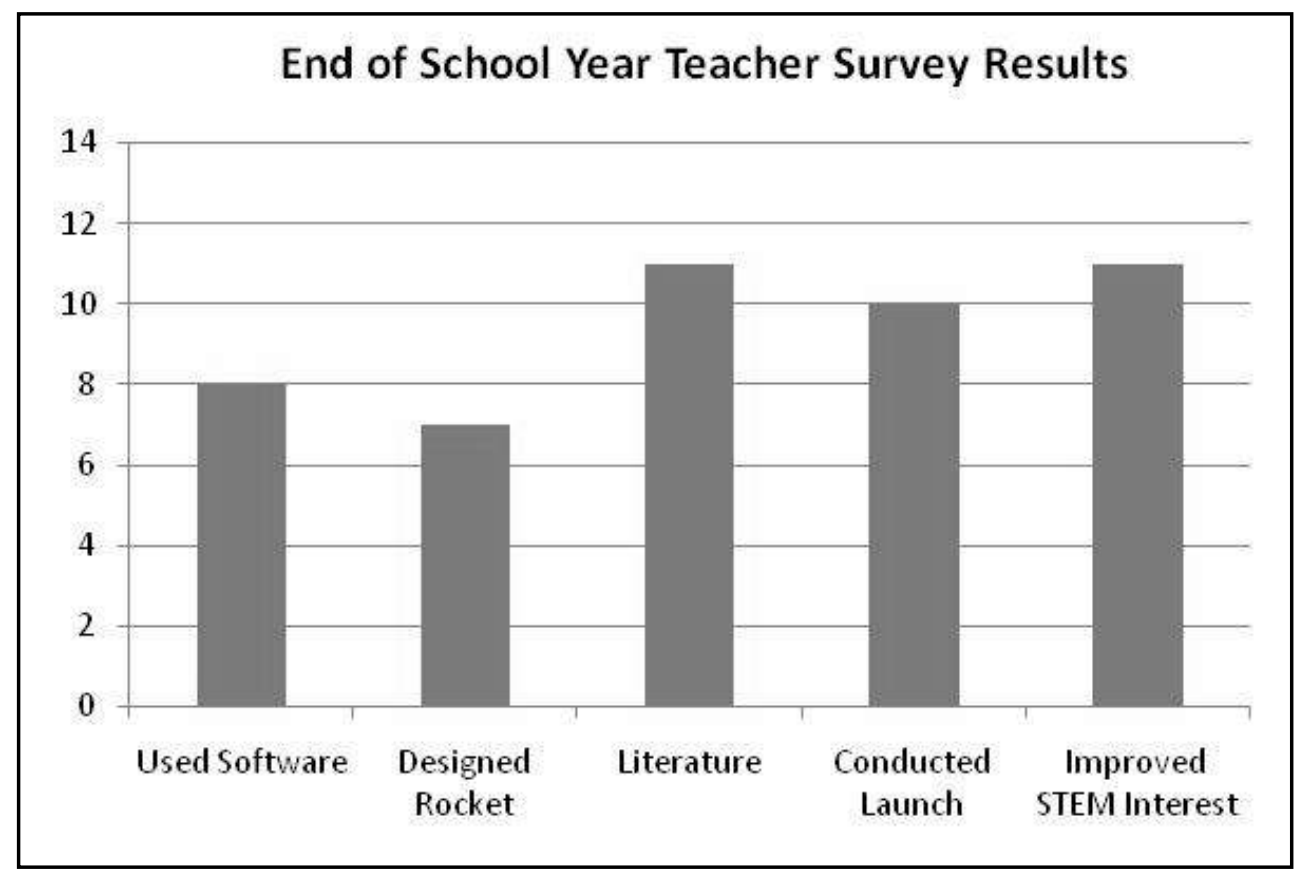

Figure 8. End of school year survey results from educators. 
The following is one example cited from a workshop participant in the end of school year survey:

I used the book and materials we were given to help me gain more confidence before I had my students assemble rockets for launching. I had never done this at school and had wanted to for a longtime. The experience with the rockets during the workshop really made me have enough knowledge to give it a try with my students.

I used the RockSim software with several classes. My advanced reading group read "Rocket Boys" (grade 7/8) and then launched rockets. We used RockSim to look at what would happen to the Rockets during flight. In both of my Earth Science classes (grade 7) we launched rockets in the spring, and again used RockSim to predict what would happen. It predicted that one of the rockets would launch and then crash to the ground nosecone first. That is what actually happened. Also several of my advanced science students spent time using the software on their own, it was very exciting for them and encouraged them to work on some rockets at home.

Building and launching rockets is always exciting for my students. This is a great science experience because we have successes and failures just like in all science experimentation! The students feel so empowered when they get a chance to make scientific decisions and then test what they build. We have great discussion about how scientists make building and experimentation decisions. Anytime students are actively building and experimenting they are inspired and ready to learn. Students that don't always show interest in science are active participants with hands-on activities like rocket building and launching.

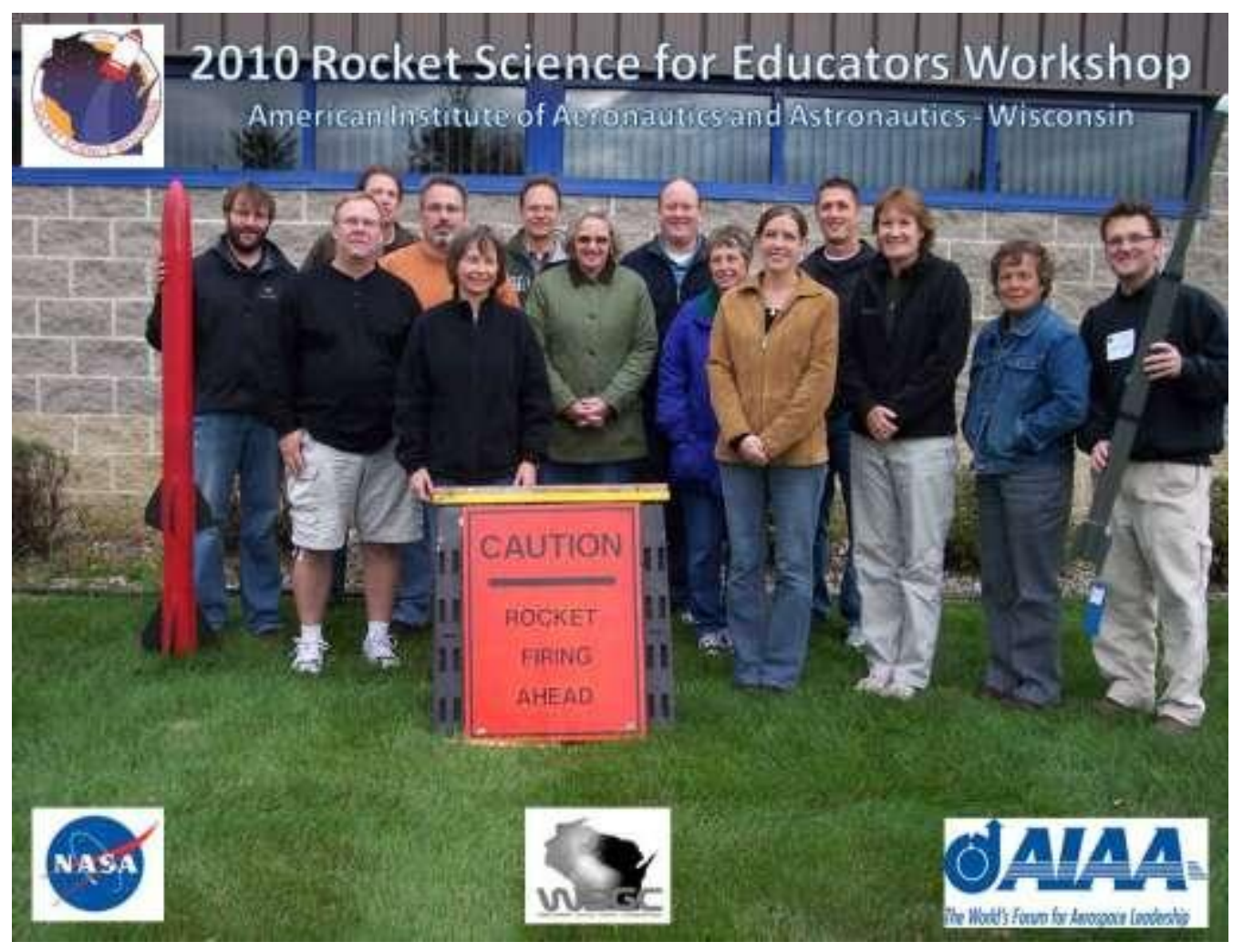

Figure 9. Educator workshop participants. 
A simple, compelling philosophy drives AIAA Wisconsin's commitment to math, science, and technology education. Make it exciting, make it empowering, and make it fun. The Rocket Science for Educators workshop is a far-reaching program that targets precollege students, and the educators who inspire them. Learning starts with a teacher, a curious student, and fun in the classroom. The AIAA sponsored Rocket Science for Educators workshop provide educators with first-hand experience and training from real aerospace professionals that will spark students' excitement about machines ... space ... aviation ... how things work... flying $\ldots$ and why things happen. In short, all the facets of math and science. Please feel free to contact the author if you are interested in learning more about this STEM workshop. 


\section{References}

1. Chiaverini, M. J., Kuo, K. K. (2007). Fundamentals of hybrid rocket combustion and propulsion. Reston, VA: AIAA Press.

2. Fortescue, P., Stark, J., Swinerd, G. (2003). Spacecraft systems engineering (4th ed.). West Sussex, England: John

3. Wiley and Sons Ltd.

4. Miller, S. A. (2010, February 14). Engineers step up for STEM next week. Milwaukee Journal Sentinel, pp. A37.

5. RockSim software. Model rocket design and simulation software (Ver. 9.0). Purchased from: www.apogeerockets.com.

6. Colorado Springs, CO: Apogee Components.

7. Van Milligan, T. S. (1995). Developing Creativity Using Model Rockets to Teach the Techniques of Problem Solving.

8. Colorado Springs, CO: Apogee Components.

9. Van Milligan, T. S. (2008). Model rocket design and construction (3 ${ }^{\text {rd }}$ ed.). Oregon, IL: Quality Books, Inc. 